\title{
ASPECTOS GERAIS DA FORMAÇÃO DE PROFESSORES*
}

\author{
Edson do Carmo Inforsato**
}

\section{RESUMO}

Este artigo, ancorado em estudos recentes e antigos, mostra o afastamento dos cursos de formação de professores em relação aos elementos que compõem a prática profissional docente. Favorável a uma aproximação efetiva com o contexto das práticás de sala de aula, o autor defende a idéia de uma formação de professores atrelada aos problemas e necessidades da prática docente no ensino formal de $1^{\circ}$ e $2^{\circ}$ graus.

\section{INTRODUÇÃO}

A habilitação para o exercício da maioria das profissões existentes em nossa sociedade só é obtida através da freqüência a cursos desenvolvidos em escolas, nas quais os alunos permanecem por alguns anos. Embora se saiba que a formação de um bom profissional não se completa apenas através de um curso regular, basta a obtenção de um diploma para que a pessoa esteja legitimada a usufruir do direito de atuar na profissão "escolhida". Entretanto, ouve-se com freqüência - tanto dos profissionais já formados como daqueles ainda em formação - que a instituição escolar deixa muito a desejar no que se refere ao preparo adequado para o exercício desta ou daquela profissão. Nóvoa em uma análise sobre a formação de um profissional, considera que esta não se constrói por acumulação (cursos, conhecimentos e técnicas), mas por um "trabalho de reflexividade crítica sobre as práticas e de reconstrução permanente de uma identidade pessoal. Por isso é tão importante investir na pessoa e dar um estatuto ao saber da experiência"(Nóvoa, 1992, p.21). Não é sem razão que denominações como "cursos muito teóricos", "matérias de pouca prática", etc., sejam manifestações recorrentes nas ocasiões em que se pede para os profissionais avaliarem os cursos que fizeram.

O saber veiculado na maioria das instituições escolares enseja um tipo de experiência nos aprendizes que não os induz às iniciativas necessárias ao

\footnotetext{
* Artigo extraído da Tese de Doutoramento intitulada "Dificuldades de Professores Iniciantes : Elementos para um Curso de Didática", orientada pela prof $\mathrm{Dr}^{\circledR}$ Myriam Krasilchik e defendida na Faculdade de Educação da USP em março de 1995.

** Professor Assistente Doutor do Departamento de Didática da Faculdade de Ciências e Letras da UNESP, Campus de Araraquara.
}

Paidéia, FFCLRP-USP, Rib. Preto, Fev/Ago 96. 
desempenho profissional. Dominicé atenta para esse fato quando diz que "devolver à experiência o lugar que merece na aprendizagem dos conhecimentos necessários à existência (pessoal, social e profissional), passa pela constatação de que o sujeito constrói o seu saber ativamente ao longo do seu percurso de vida. Ninguém se contenta em receber o saber, como se ele fosse trazido do exterior pelos que detêm os seus segredos formais. A noção de experiência mobiliza uma pedagogia interativa e dialógica"( Dominicé, 1986, p.65). São raros os cursos em que o aluno tem oportunidades efetivas de se manifestar, expressando os seus pontos de vista, demonstrando suas habilidades, colocando suas dúvidas, solucionando problemas por ele enunciados, etc. A pedagogia referida por Dominicé tem embasamento teórico sustentável e tem também difundido em escala considerável seus pressupostos e suas propostas metodológicas. No entanto, é ainda tênue a inserção desses pressupostos e dessas metodologias no âmbito escolar. As iniciativas, quando existem, são isoladas e acabam por estiolar-se por falta de apoio e, também, por falta de condições motivadoras propícias para seu prosseguimento e conseqüente ampliação. Como mostram os trabalhos de Casagrande (1972), Mizukami (1986) e Dias da Silva (1992), o modelo tradicional ainda impera na prática escolar cotidiana. Digase, a bem da verdade, que usarmos a designação de modelo tradicional ou mesmo didática tradicional para as práticas pedagógicas normalmente verificadas nas salas de aula das escolas, sejam elas públicas ou particulares, é um abuso de linguagem. A didática tradicional é caracterizada por um conjunto fixo e rigoroso de regras. A propósito, sobre isso, diz Perrenoud: "Podemos designar por didática tradicional a alternância bem conhecida de lições e momentos de controle das aquisições. Progredindo no texto do saber, texto que ele próprio estabeleceu, ou que já recebeu constituído, o professor aborda sucessivamente ao longo do ano escolar os diversos capítulos do programa. Explica novas noções, expõe novos conhecimentos, introduz novos saber-fazer; define a terminologia correspondente e fá-la (sic) anotar e memorizar; enuncia e faz repetir fatos, regras ou teoremas; dá exemplos, mostra objetos ou ilustrações; assegura-se por meio de um questionário que os alunos compreendem as explicações e memorizam o essencial. Nesta fase - a lição - os alunos não estão passivos mas o professor desempenha o papel principal, pedindo acima de tudo a sua atenção e, por vezes, a sua participação num trabalho em que é o principal organizador. Assim que as noções são introduzidas, os alunos são convidados a fazer exercícios por vezes oralmente, freqüentemente por escrito, a partir de instruções ditadas, anotadas no quadro ou impressas nos manuais ou nos livros escolares. Lições e exercícios combinamse em proporções variáveis para cobrir as noções constitutivas de um capítulo do plano de estudos. Quando o professor julga que um número suficiente de 
alunos compreendeu ou apreendeu, interroga-os oralmente ou submete-os a uma prova escrita. Esta avaliação, além de ser formalmente comunicada aos alunos ou aos pais, permite ao professor voltar a página, e abordar um novo capítulo do programa"(Perrenoud, 1993, pp.77 e 78).

A caracterização acima da didática tradicional é bastante precisa e por ela percebemos que aquilo que se verifica nas escolas como prática pedagógica guarda relações com esse modelo didático mas está longe de corresponder à totalidade dele. Com base nisso, das autoras referidas em parágrafo anterior, Dias da Silva (1992) é a mais reticente em afirmar que o modelo da didática tradicional impera de maneira plena em nossas escolas. Para ela - e nisso concordo - a prática pedagógica nas salas de aula se reveste de um misto de aspectos da didática tradicional e improvisações arrumadas dentro das circunstâncias que aparecem no trabalho cotidiano. Aliás, ainda segundo a autora, as improvisações são mais freqüentes que os aspectos da didática tradicional. Em todo o caso, esta autora não nega a centralização pedagógica na figura do professor. Por essas considerações vê-se que o professor ainda é de uma importância fundamental no sistema escolar. Basicamente é ele quem determina toda a prática pedagógica que ocorre nas salas de aula. Portanto, qualquer iniciativa de reforma das práticas pedagógicas terá que, necessariamente, contemplar a formação dos professores, tanto daqueles que já estão em serviço, quanto daqueles que estão se preparando para assumir a profissão. No entanto, inúmeros estudos, e mesmo observações assistemáticas,constatam a precariedade da formação de nossos professores* . É certo que um dos fatores responsáveis por tal precariedade é a falta de identificação observada na maioria dos jovens em relação a esta profissão. A descaracterização da profissão do professor é o fator preponderante da ausência de identificação referida. Essa minha afirmação baseia-se em

\footnotetext{
* Alguns dos Congressos e simpósios da área de educação ocorridos na década de 80 abordaram o tema da formação do professor. Destacamos, entre estes, o I Simpósio de Educação Universitária do Instituto de Letras, Ciências Sociais e Educação - UNESP - Araraquara, de 9 a 12 de maio de 1988. As principais atividades realizadas neste simpósio estão registradas em "Pensando a Educação - Ensaios sobre a formação do Professor e Política Educacional" Editora da UNESP, São Paulo, 1989. Outros registros que destacamos mostrando a situação precária de formação dos professores encontram-se em "Formação do professor - Atualizando o Debate - Maristela V.C. Bernardo (org.). Série Cadernos. PUC-EDUC, São Paulo, 1989. Na atual década - 90 - assume vulto significativo no tratamento desse tema o Congresso Estadual Paulista sobre a formação de Educadores realizado em Águas de São Pedro nos anos de 1992, 1993 e 1994. Os principais resultados do último Congresso encontram-se em CONGRESSO ESTADUAL PAULISTA sobre a formação de educadores, 3, Águas de São Pedro, 1994. Formação de Educadores tempo da escola, tempo da sociedade, 3: anais. São Paulo, UNESP, 1994. 330p.
}

Paidéia, FFCLRP-USP, Rib. Preto, Fev/Ago 96. 
Ginsburg que, numa comparação entre a profissionalização e a proletarização, diz o seguinte: "a profissionalização é um processo através do qual os trabalhadores melhoram seu estatuto, elevam seus rendimentos e aumentam o seu poder-autonomia. Ao invés, a proletarização provoca uma degradação do estatuto, dos rendimentos e do poder-autonomia. É útil sublinhar quatro elementos deste último processo: a separação entre a concepção e a execução, a estandardização das tarefas, a redução dos custos necessários à força de trabalho e a intensificação das exigências em relação à atividade laboral"( Ginsburg, 1990, p.315).

A proletarização dos professores, sobretudo daqueles que atuam na rede pública de primeiro e segundo graus, é um fato inquestionável. Este fato constituise numa forte razão para o afastamento dos jovens da carreira docente, pois evidentemente ningúem opta por uma profissão sabendo-a desprestigiada $e$ desprovida de perpectivas futuras. Mas a denominada "formação pedagógica" tem seu grau de responsabilidade no despreparo acima apontado. Zaia Brandão (1982) constatou, numa amostra de professores, que estes se referiram à formação pedagógica que tiveram como pouco eficaz para o desenvolvimento de seu trabalho nas circunstâncias que envolvem o ensino de primeiro e segundo graus. Tanto assim que os livros referentes às disciplinas pedagógicas somente eram usados nas ocasiões em que eles, professores, tinham que se submeter a concursos públicos. Isto mostra que as disciplinas pedagógicas são desenvolvidas com a mesma sistemática das disciplinas de qualquer outro conteúdo: como estas, aquelas também são auto-referentes. Esta inadequabilidade do saber escolar em relação às práticas efetivas necessárias ao desempenho profissional é resultado de uma visão e de uma prática escolar que têm levado a formação profissional a certos tipos de impasses. Schön (1992) analisando a crise de confiança no conhecimento profissional, considera que esta crise está centralizada num conflito entre o "saber-escolar" e a "reflexão-na-ação" dos professores e alunos. Diz ele que "existe, primeiro que tudo, a noção de saber escolar, isto é, um tipo de conhecimento que os professores são supostos conhecer e transmitir aos alunos. É uma visão dos saberes como fatos e teorias aceites, como proposições estabelecidas na sequiência de pesquisas. O saber-escolar é tido como certo, significando uma profunda e quase mística crença em respostas exatas. É molecular, feito de peças isoladas, que podem ser combinadas em sistemas cada vez mais elaborados, de modo a formar um conhecimento avançado. A progressão dos níveis mais elementares para os níveis mais avançados é vista como um movimento das unidades básicas para sua combinação em estruturas complexas de conhecimento" (Schön, 1992, p.81).

Outra característica salientada por Schön refere-se ao sentido 
"categorial" do saber escolar. As pessoas que têm melhor desempenho num curso regular, são aquelas que conseguem mais rapidamente dar respostas certas a situações que normalmente se constituem na apresentação de objetos, conceitos e idéias que devem ser classificadas, colocadas em fórmulas pré-estabelecidas, seriadas segundo critérios também pré-estabelecidos, etc.

As disciplinas pedagógicas, tal como tem sido desenvolvidas nos cursos de licenciatura, também se encaixam nesta visão, e porque não dizer, prạ́tica escolar. Quer dizer: os alunos, durante a sua preparação pedagógica, têm poucas oportunidades de interagir com as atividades referentes ao trabalho de um professor, e, também, de debater os problemas enfrentados por um professor no seu dia-a-dia. As questões colocadas para o aluno são alheias a ele, vindas de fora, não possibilitando, assim, a emergência de motivações para o aprendizado de habilidades relevantes para o ato de ensinar.

Em um levantamento que fiz ao longo dos últimos 7 anos a respeito das expectativas dos alunos de licenciatura com relação ao curso de didática*, constatei que a maioria deles manifesta a esperança de que o curso lhes dê condições reais de enfrentar a difícil tarefa de ensinar. Quanto às reflexões, as expectativas são de que estas estejam direcionadas para os problemas enfrentados pelas escolas públicas de primeiro e segundo graus.

Reflexão sobre os problemas enfrentados pelos professores em ação, no seu dia-a-dia, significa estar observando e, também, participando desta ação. Isto quer dizer que os alunos em formação devem ter oportunidades, as mais freqüentes possíveis, de travar contato efetivo com os professores nos seus atos profissionais diários. Não para julgar os professores, segundo teorias préconcebidas, mas, sim, para tentar colocar-se no lugar deles, e, a partir daí tecer suas considerações e representações a respeito das práticas pedagógicas. As representações assim conseguidas serão mais "figurativas" que "formais"**, posto que implicarão agrupamentos situacionais contextualizados e, por isto mesmo, capazes de estabelecer relações mais próximas das experiências cotidianas. Esta maneira, acredito, é a mais adequada para se construírem noções que dão referências e direcionamentos para as ações. Isto, a meu ver, é construir uma teoria a partir da prática. Busco auxílio novamente em Schön (1992) que ilustra de modo singelo o que afirmei acima: "No Massachussets Institute of Technology tive a oportunidade de estudar os esforços realizados por alguns engenheiros para construir computadores aplicáveis ao estudo da engenharia.

* Levantamento obtido através de questionário aplicado a alunos de vários cursos de Licenciatura da Faculdade de Ciências e Letras da UNESP - Araraquara, de 1985 a 1992.

** Estas designaçōes foram feitas por Donald Schon e por Jeanne Bamberger, in Nóvoa, A. op. cit., p. 85 .

Paidéia, FFCLRP-USP, Rib. Preto, Fev/Ago 96. 
Uma trabalho, muito interessante, feito por John Slater, é um programa informático chamado "Growltiger", que permite desenhar estruturas tais como uma ponte um andaime. $\mathrm{O}$ utilizador tem de especificar as cargas a serem aplicadas sobre a estrutura, após o que um programa inserido no sistema analisará rapidamente como a estrutura se deforma com o peso, produzindo uma representação visual dessas deformações. Como todo este processo se desenrola rapidamente, o estudante pode fazer experiências, pode formular perguntas e pode observar como as deformações se alteram. Alguns estudantes que utilizaram o programa afirmam que, apesar de terem estudado e de saberem a teoria das estruturas, não tinham tido, até esse momento, a noção do comportamento de uma estrutura, como se quisessem dizer: eu devia saber a teoria, estudei-a e posso até dizer as fórmulas. Mas não tinha, realmente, compreendido como ela funcionava até ter feito estas experiências, uma após outra, e ter observado os resultados. De certo modo, o fato de se saber a teoria, no sentido de saber as proposições relevantes, e as fórmulas, não é o mesmo do que ter a noção do comportamento da estrutura, o que permite antecipar como ela se deformará com o peso"(Schön, 1992, p.84).

Nossos cursos de graduação, quaisquer que sejam, orientam-se por uma excessiva tonalidade livresca, na qual o texto costuma ser o ponto de partida para o desenvolvimento dos assuntos e dos temas, dando mostras inequívocas da nossa tradição bacharelesca. Minha convicção é a de que o texto deve ser introduzido após a enunciação das questões e dos problemas. Ele deve se converter num subsídio importante para o aclaramento e para a busca de equacionamento das situações enfrentadas. Recorro aqui à obra clássica de Gusdorf na qual, entre tantas outras coisas, ele afirma que "o homem é o ponto de partida e o ponto de chegada de toda tentativa de conhecimento. Não é a ciência do homem que funda o homem; é o homem sempre que se procura a si mesmo através dos diversos empreendimentos"( Gusdorf, 1967, p.301).

Ainda com respeito a minha convicção de que a formação pedagógica deve privilegiar as oportunidades efetivas de ação, apoio-me em Bettelheim que num ensaio seminal a respeito dos requisitos necessários para a pessoa se tornar um psicoterapeuta diz: "minhas experiências com a psicanálise me convenceram de que não é o domínio teórico de um problema que permite sua maior compreensão. São as experiências interiores que permitem alcançar uma percepção da totalidade envolvida nas experiências interiores de outros, um conhecimento que pode, então, se tornar a base de estudos teóricos"(Bettelheim, 1991, p.36).

A formação profissional, qualquer que seja ela, precisa acontecer precipuamente num lugar que explicita a gramática da profissão. Isto é, os 
sujeitos que estão em formação devem ter oportunidades de manipular os instrumentos, os conceitos, as decisões, ou seja lá o que for, para que ele possa adquirir um mínimo de desenvoltura na profissão almejada. Este lugar denominado "practicum"*, permite ao sujeito fazer, tentar, errar, voltar atrás, e ver o que fez, fazer alterações, etc.

De certa maneira esta concepção de formação esbarra na concepção de "racionalidade técnica" que impera nas organizações escolares. Segundo Pérez Gomez, "trata-se de uma concepção epistemológica da prática, herdada do positivismo, que prevaleceu ao longo de todo o século XX, servindo de referência para a educação e socialização dos profissionais em geral e dos docentes em particular. Segundo o modelo da 'racionalidade técnica', a atividade do profissional é, sobretudo, instrumental, dirigida para a solução de problemas mediante a aplicação rigorosa de teorias e técnicas científicas"(Perez Gomez, 1992, p.98).

O curriculum para formação profissional dentro deste modelo de racionalidade técnica segue o seguinte esquema de acordo com Bordenave(1984)** :

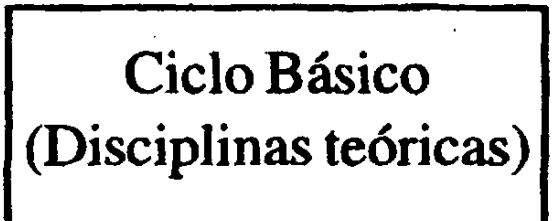
Ciclo profissional. (Disciplinas teórico- práticas)

\begin{tabular}{c} 
Ciclo de \\
especialização. \\
(Disciplinas práticas) \\
\hline
\end{tabular}

Transpondo esta representação para a formação de professores, teríamos a seguinte configuração:

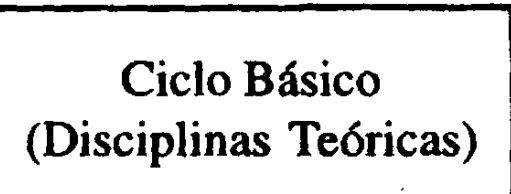

Formação Pedagógica

(Disciplinas Teóricas + Estágios)

Vê-se, portanto, que há uma correspondência quase que isomórfica entre qualquer formação profissional e a formação dos professores. Tanto naquela como nesta, o profissional, quando muito, adquire um bom instrumental teórico, cuja aplicação se faz somente em situações artificiais, onde as condições

* Denominação de Donald Schon em NóVOA, A. op. cit. p. 89.

** BORDENAVE, J. e PEREIRA, A.M. Estratégias de Ensino Aprendizagem, Rio de Janeiro, Vozes, 1984, p. 75.

Paidéia, FFCLRP-USP, Rib. Preto, Fev/Ago 96. 
complexas são deixadas de lado, A redução da racionalidade prática a uma mera racionalidade instrumental, obriga o profissional a aceitar a definição externa das metas da sua intervenção. Como conseqüência, há o aumento do planejamento centralizado. Isto é, há um corpo de especialistas com os mais elevados conhecimentos teóricos, estabelecendo regras e procedimentos para os técnicos aplicarem em seus campos de trabalho. $\mathrm{Na}$ área educativa há os órgãos responsáveis pela elaboração e implantação de reformas, que definem normas para serem executadas pelos profissionais que atuam naquelas unidades que se situam na posição mais inferior da hierarquia: as unidades escolares.

Martins (1987), num estudo sobre a relação entre a didática como disciplina de formação de professores e a organização do trabalho na escola, diz que essa disciplina, ao não priorizar, em seu conteúdo, os aspectos presentes na organização escolar, dá a ilusão de que o professor é um profissional liberal, quando, na verdade, a autonomia do professores sobre o seu trabalho é mínima. Deste modo, "a Didática Teórica prepara o professor para ser um profissional liberal que detém o controle do processo e produto do seu trabalho, ou seja, que pensa e executa; que concebe, executa e controla o seu processo de ensino. Enquanto a Didática Prática ocorre numa organização do trabalho em que o professor é um assalariado do ensino e, na hierarquia de funções dentro da escola, ocupa a posição de executor de tarefas, não detendo, portanto, o controle do seu processo de ensino, bem como dos seus resultados"(Martins, 1987, p.76).

Portanto, há uma lógica dentro da concepção de racionalidade técnica, que determina tanto a formação como a atuação dos profissionais.

Embora esta concepção tenha feito progressos em relação às concepções mais tradicionalistas, há pontos de estrangulamento em sua vigência que têm avolumado as situações de impasse das práticas e das formações profissionais. Para ficar apenas em algumas destas situações, basta atentarmos para a falta de interesse e de motivação que manifestam os alunos nos seus cursos profissionalizantes, e, ainda, atentarmos para alguns resultados catastróficos oriundos da intervenção profissional em empresas, clínicas, hospitais, e, sobretudo, em escolas.

Há pontos de vista, ainda dentro desta concepção de racionalidade técnica mais flexíveis e que levam em conta a complexidade das práticas profissionais no âmbito das ciências sociais, particularmente no âmbito do ensino. Pérez Gomez (1992) cita Gage $(1978,1986)$, como um dos que "sugere que as atividades práticas como o ensino têm uma dimensão científica e uma dimensão artística. O ensino, tal como a medicina ou engenharia, pode elaborar a sua fundamentação científica apoiando-se no conhecimento produzido pela investigação, tarefa que Gage considera prioritária"(Pérez-Gomez,1992, p.99). Mas o próprio Pérez 
Gomez faz uma ressalva com o seguinte teor: "todavia, é preciso sublinhar a necessidade de, em primeiro lugar, determinar qual das diferentes aproximações teóricas é a mais adequada à produção de uma ciência do ensino; em segundo lugar, deixar bem claro que a analogia do ensino com a medicina e com a engenharia é bastante frágil, na medida em que a riqueza dos processos de ensino e aprendizagem reside na interação mental e social e na singularidade subjetiva que a caracteriza; em terceiro lugar, considerar o componente artístico que está presente no cotidiano educativo e que é subvalorizado pela racionalidade técnica; em quarto lugar, lembrar que as derivações normativas da racionalidade técnica tipificaram uma proposta rígida para a formação de professores, centrada no desenvolvimento de competências e capacidades técnicas"(Perez Gomez,1992, p.99).

Não se trata de desprezar a formação técnica dos professores, posto que, sem ela, as intervenções na prática educativa se tornam lacunares, e, às vezes, impossível. O que se torna problemático é encarar a formação como prioritariamente técnica. Acredito que tal formação deva ser vista de maneira que as atividades desenvolvidas ao longo de seu curso sejam momentos propiciadores para que as pessoas ajam e, ao mesmo tempo, reflitam sobre seus modos de agir.

É meu pressuposto, portanto, que uma formação profissional adequada se dá com base no desenvolvimento de atividades que coloquem o aluno em interação permanente com os aspectos relevantes desta profissão. Especificamente, com relação à formação do professor, acredito que ela deva se pautar pelo esforço permanente em se colocar o aluno em situações de sala de aula, em qualquer grau. Tanto para observar com critério e intensidade as. ocorrências do cotidiano, como para iniciar-se na tarefa da docência, enfrentando os seus percalços, descobrindo maneiras de ensinar melhor, enfim, preparandose adequadamente para ser um profissional que não se frustre na primera tentativa de exercer sua profissão.

\section{REFERÊNCIAS BIBLIOGRÁFICAS}

BERNARDO, M. C. V. (org.). ( 1989a). Pensando a educação - Ensaios sobre a formação do professor e política educacional. São Paulo: Editora da Unesp.

(1989b). Formação do professor - Atualizando o debate. São Paulo: Série Cadernos PUC - EDUC.

BETTELHEIM, B. (1991). A Viena de Freud e outros ensaios. Rio de Janeiro: Editora Campus.

BORDENAVE, J. e PEREIRA, A.M. (1984). Estratégias de ensino - aprendizagem. Petrópolis: Vozes.

BRANDÃO, Z. (1982). Abordagens alternativas para o ensino de didática. In:

Paidéia, FFCLRP-USP, Rib. Preto, Fev/Ago 96. 
CANDAU, Vera. A didática em questão. Petrópolis: Vozes.

CASAGRANDE, L. (1972). Reforma escolar e didática: Exploração do conceito ensino. Tese de doutoramento. FFCLRP-USP

CONGRESSO ESTADUAL PAULISTA SOBRE A FORMAÇÃO DE EUDUCADORES. (1994). Formação de Educadores, tempo da escola, tempo da sociedade, $3^{\circ}$ : Anais. São Paulo, UNESP.

DIAS DA SILVA, M. H. G. F. (1992). O professor como sujeito do fazer docente: $A$ prática pedagógica nas $5^{a}$ séries. Tese de Doutoramento. São Paulo: Faculdade de Educação da USP.

DOMINICÉ, P. ( 1986). La formation continué est aussi un reglement de compte avec sa escolarité. Paris: Educacion et Recherche - 3/ 86.

GINSBURG, M. (1990). El processo de trabajo y la acción política de los educadores: un análisis comparado. Madrid: Revista de Educacion, $\mathrm{n}^{\circ}$ extraordinário.

GUSDORF, G. (1967). Professores para quê ? Trad. João Bernard da Costa e Antonio Ramos Rosa. Lisboa: Livraria Morais Editora.

HEGENBERG, L. (1974). Definiçôes: termos teóricos e significados. SP: Cultrix e Edusp.

MARTINS, P. L. de O. (1987). A didática na atual organização do trabalho na escola. Dissertação de Mestrado. Belo Horizonte: UFMG - Faculdade de Educação.

MIZUKAMI, M das G. (1986). Ensino: as abordagens do processo. SP: E. P.U..

NÓVOA, A. (1992). A formação de professores e profissão docente. In: NÓVOA, A.

(coord.). Os professores e sua formação. Lisboa: Dom Quixote.

PAGOTTO, M.D. (1988) Formação e Atuação: um estudo sobre a representação dos professores. Dissertação de Mestrado. São Carlos: UFSCar.

PEREZ GOMEZ, A. (1992). O pensamento prático do professor: a formação do professor como profissional reflexivo.In: NÓVOA, Antonio. Os professores e sua formação. Lisboa: Editora Dom Quixote.

PERRENOUD, P. (1993). Práticas pedagógicas, profissão docente e formação. Lisboa: Dom Quixote.

SCHÖN, D. (1992). Formar professores como profissionais reflexivos.In: NÓVOA, Antonio (coord.).Os professores e sua formação. Lisboa: Editora Dom Quixot

\section{ABSTRACT}

This article discuss the theoretical and abstract nature of the teacher education in relation of concret educational reality. Drawing on the ideas of authors which discuss the relationship between theory and practice, the author of this article point out the necessity of rethink of teacher education taking in account the real context and problems of in service teachers.

Key- Words: Teaching Procedures-Teachers' Profissionalization-Curriculum Palavras - Chave: Prática Docente - Formação de Professores - Currículo. 